\title{
Expansion of NK cells from PBMCs using immobilized 4-1BBL and interleukin-21
}

\author{
XIAOMEI LI ${ }^{1,3}$, CHENHUI HE $^{1}$, CHANGZHEN LIU ${ }^{1}$, JUAN MA ${ }^{1}$, \\ PAN MA $^{1,3}$, HONGLIAN CUI ${ }^{1}$, HUA TAO $^{1}$ and BIN GAO $^{1,2}$ \\ ${ }^{1}$ CAS Key Laboratory of Pathogenic Microbiology and Immunology (CASPMI), ${ }^{2}$ China-Japan Joint Laboratory \\ of Molecular Immunology and Microbiology, Institute of Microbiology, Chinese Academy of Sciences, \\ Beijing 100101; ${ }^{3}$ University of Chinese Academy of Sciences, Beijing 100049, P.R. China
}

Received February 21, 2015; Accepted April 2, 2015

DOI: 10.3892/ijo.2015.3005

\begin{abstract}
Adoptive transfer of NK cells has been widely applied clinically for cancer immunotherapy. However, the difficulties to obtain a large number of activated NK cells impede the successful application of such therapy. In the present study, we implemented a novel method involving the use of immobilized human 4-1BBL and interleukin-21 to amplify NK cells from the peripheral blood mononuclear cells (PBMCs) of healthy donors. Following stimulation for 21 days, we achieved considerable expansion of NK cells with high purity and strong cytotoxicity. This is the first time solid phase cytokines were used to augment NK cells, and this method has the advantage of no need to introduce feeder cells, without prior purification of NK cells and it effectively stimulated and expanded NK cells. The strategy of cell proliferation and activation could lead to a safer and more effective application of NK cells clinically.
\end{abstract}

\section{Introduction}

Natural killer cells (NK cells), a subset of approximately 5-15\% of the peripheral blood lymphocyte population, based on the expression levels of surface markers, are classified into two subpopulations with different functions, CD3 ${ }^{-} \mathrm{CD} 56^{\mathrm{dim}} \mathrm{CD} 16^{+}$ (90\%) and CD3- CD56 ${ }^{\text {bright }}{ }^{-}$D16- (10\%) (1-4). NK cells typically lack antigen-specific cell surface receptors (5), consistent with the fact that NK cells do not require tumor-specific antigen recognition when killing tumor cells. This advantage of NK cells compared with $\mathrm{T}$ and $\mathrm{B}$ cells has led many scientists to study the immunotherapeutic effects of NK cells $(6,7)$. In recent years, NK cell-based adoptive immunotherapy to treat cancer has become increasingly important $(6,8-10)$. However,

Correspondence to: Professor Bin Gao, The Centre for Molecular Immunology, Institute of Microbiology, Chinese Academy of Sciences, 1 Beichen West Road, Beijing 100101, P.R. China

E-mail: bgao2004@gmail.com

Key words: 4-1BBL, interleukin-21, immobilization, NK cells progress in the development of this therapy is hindered by the lack of a feasible method to expand large numbers of highly cytotoxic NK cells ex vivo (11). Previous studies have examined various methods to amplify NK cells. Using a starting population of $\mathrm{CD}^{2} 6^{+}$-selected PBMCs stimulated with cytokines alone, Klingemann et al gained only 5- to 40-fold NK expansion (12), whereas Berg et al used the same starting population but added EBV-LCL as feeder cells and obtained 300- to 930-fold NK expansion in 15 days, with $98 \%$ NK purity (13). Other studies have utilized unseparated PBMCs as the initial expanded population, but typically also include feeder cells, such as the K562 cell line expressing IL-15 and 4-1BBL on the surface (14), and K562 cell line with membrane-bound IL-21 (15), achieving tens of thousands of times greater expansion of NK cells with nearly $80 \%$ purity. In addition, Carlens et al obtained 193-fold expansion, but only 55\% NK purity, using unseparated PBMCs stimulated with cytokines alone without feeder cells (16).

4-1BBL, also known as CD137L or TNFSF9, a member of the tumor necrosis factor ligand superfamily, is expressed in $\mathrm{B}$ cells, dendritic cells, activated T cells and macrophages. This protein binds to the receptor $4-1 \mathrm{BB}$, generating a co-stimulatory signal for $\mathrm{T}$ cell activation and expansion $(17,18)$. Although 4-1BB is typically expressed on activated but not resting T-cells $(19,20)$, this receptor has also been detected on NK cells (21). The functional domain of 4-1BBL is located in the extracellular domain $(22,23)$, and soluble 4-1BBL has no activity compared with the natural membranebound form (24). Interleukin-21 (IL-21) has been recently identified, and the functional effects of this protein on the immune system have been recently studied (25). IL-21, a secreted protein, mediates the proliferation, differentiation and antitumorigenicity of cells via binding to a composite receptor comprising the private receptor IL-21R, which is also expressed on a variety of B, T, NK cell lines, and the common receptor $\gamma$-chain, which is also shared by IL-2, IL-4, IL-7, IL-9, IL-13 and IL-15 (26-29). Wang et al used these two receptor molecules, which were expressed on the feeder cells, to stimulate the expansion of NK cells and achieved significant cell expansion (30). However, a disadvantage of this method is the effective removal of the feeder cells from the activated NK cells. 
In the present study, we introduced a novel strategy involving solid phase recombinant human 4-1BBL and IL-21 to expand NK cells using the PBMCs from healthy donors, and this method does not require separation from other cells. Here, the recombinant human extracellular domains of 4-1BBL and IL-21 were, respectively expressed in E. coli as BirA-tagged recombinant proteins. After biotinylation, the two protein factors were bound to streptavidin-labeled Dynabeads to constitute the objective irritant. This objective irritant was used to stimulate human PBMCs three times in 21 days, achieving considerable NK fold-expansion, high purity, and nearly $100 \%$ potent cytotoxicity of NK cells. Moreover, the advantage of removing the beads co-cultured with NK cells using a magnetic separation rack prevents the contamination of other components of the co-culture system, such as feeder cells.

\section{Materials and methods}

Materials and reagents. The restriction enzymes, including BamHI, NdeI, XhoI, and Pfu DNA polymerase used in the present study were purchased from Tiangen Biotech Co., Ltd. (Beijing, China). The T4 DNA ligase and the ligase buffer were purchased from Fermentas. All primers used in the PCR experiments were synthesized at Invitrogen Co., Ltd. (Shanghai, China), and the recombinant plasmids were also sequenced at Invitrogen. The protein marker was purchased from GenStar Biosolutions Co., Ltd. (Beijing, China). Streptavidin was purchased from Tianjin Heowns, Biochemical Technology Co., Ltd. (Tianjin, China). Dynabeads ${ }^{\circledR}$ M-280 Streptavidin was purchased from Invitrogen Co., Ltd. (Shanghai, China). $\mathrm{X}-\mathrm{VIVO}^{\mathrm{TM}} 15$ medium was purchased from Sartorius Stedim Biotech GmbH. The FITC-conjugated anti-human CD3 monoclonal antibody was purchased from Biolegend, and APC-conjugated anti-human CD56 monoclonal antibody was purchased from Miltenyi Biotec. Human AB serum was purchased from Andygene Co. (USA). Fetal bovine serum (FBS) was purchased from Molecular Devices (USA).

Plasmids, strains, cells and cell lines. The plasmids pGEX-6p-1 and pET-28a and E. coli strains DH5 $\alpha$ and BL21 (DE3) were obtained from our laboratory. We isolated PBMCs from the concentrated human leukocyte blood of healthy donors provided at the Beijing Red Cross Blood Center. The cell line K562 transformed into luciferase plasmid (K562-luc cells) was also obtained from our laboratory.

Plasmid constructs. To generate the plasmid construct pGEX-6p-1-h4-1BBL-BirA-tag, we fused the BirA-tag gene to the N-terminus of the 184-amino acid extracellular domain of human 4-1BBL. There is a (GGGGS)3 linker between h4-1BBL and BirA-tag. Overlap PCR was used for target gene amplification, and we inserted the target gene between the BamHI and XhoI restriction sites in the plasmid pGEX-6p-1. In addition, we amplified the human IL-21 gene without the signal peptide and generated a C-terminal BirA-tagged fusion protein, with a linker bridging IL-21 and the BirA-tag, as described above. The target gene was also amplified using overlap PCR, however, the target gene was inserted between the NdeI and XhoI restriction sites in pET-28a to generate the recombinant plasmid pET-28a-hIL-21-BirA-tag. The primers used to PCR amplify the target genes are shown in Table I.

Expression and purification of protein. To express the proteins h4-1BBL and hIL-21, the recombinant plasmids pGEX-6p1-h4-1BBL-BirA-tag and pET-28a-hIL-21-BirA-tag were transformed into E. coli strain BL21 (DE3) through heat shock transformation. To express h4-1BBL, the cells were grown for $8 \mathrm{~h}$ at $37^{\circ} \mathrm{C}$ from a single colony in $5 \mathrm{ml} \mathrm{LB}$ medium supplemented with $50 \mu \mathrm{g} / \mathrm{ml}$ of ampicillin. Subsequently, the cells were diluted 100 -fold into $300 \mathrm{ml}$ of fresh medium (supplemented as above) and 40-fold into two liters of fresh medium (supplemented as above) and incubated at $37^{\circ} \mathrm{C}$ with shaking at $200 \mathrm{rpm}$ until reaching an OD600 of 0.6. Protein expression was induced upon the addition of $1 \mathrm{mM}$ IPTG. The cells were grown at $25^{\circ} \mathrm{C}$ for $5 \mathrm{~h}$ and subsequently harvested through centrifugation. To express hIL-21, the single colony propagation was performed as described for h4-1BBL, but the medium was supplemented with $50 \mu \mathrm{g} / \mathrm{ml}$ of kanamycin. When the OD600 reached 0.8 , the culture was induced with $1 \mathrm{mM}$ IPTG and subsequently incubated overnight at $37^{\circ} \mathrm{C}$. The protein expression was examined using $12 \%$ sodium dodecyl sulfate polyacrylamide gel electrophoresis (SDS-PAGE).

To purify h4-1BBL-BirA-tag protein, the harvested cells were lysed using ultrasonication. The GST-h4-1BBL fusion protein was harvested from the supernatant using Glutathione Sepharose 4 Fast Flow according to the manufacturer's instructions. The GST-tag was cleaved using precision protease (PSP) on the column at $4^{\circ} \mathrm{C}$ overnight, and the target protein was purified through fast protein liquid chromatography (FPLC). To purify hIL-21-BirA-tag protein, we obtained the inclusion bodies after lysing the cells, and refolded the proteins using the rapid dilution method. Subsequently, we concentrated the protein from the refolding buffer using Ultrafiltration concentration tubes $(10 \mathrm{kDa})$, followed by FPLC.

Protein biotinylation. Several solutions were used for protein biotinylation: biotin-protein ligase ( $3 \mathrm{mg} / \mathrm{ml}$ BirA enzyme); Solution A (0.5 M bicine buffer, pH 8.3); Solution B (100 mM ATP, $100 \mathrm{mM} \mathrm{MgOAc}$, and $200 \mathrm{mM}$ biotin); extra D-biotin (500 $\mathrm{mM}$ biotin); pepstatin ( $2 \mathrm{mg} / \mathrm{ml}$ in DMSO) and leupeptin $\left(2 \mathrm{mg} / \mathrm{ml}\right.$ in $\mathrm{dH}_{2} \mathrm{O}$ ). The biotinylation reaction system included $700 \mu \mathrm{l}$ of target protein (1-2 mg), $100 \mu \mathrm{l}$ Solution A, $100 \mu \mathrm{l}$ Solution B, $100 \mu 1$ extra D-biotin, $50 \mu 1$ BirA enzyme, $2 \mu 1$ pepstatin and $2 \mu \mathrm{l}$ leupeptin. The reaction was incubated overnight at $25^{\circ} \mathrm{C}$. For biotinylated h4-1BBL-BirA-tag (h4-1BBL-BirA-tag-biotin) protein was directly purified through FPLC. However, the biotinylated hIL-21-BirA-tag (hIL-21-BirA-tag-biotin) protein was purified using Ni-NTA, followed by FPLC.

SA electrophoretic mobility shift assay. We used 3 EP tubes $(1.5 \mathrm{ml})$ to conduct this assay. Two tubes were filled with either moderate biotinylated protein or SA, and equal amounts of both biotinylated protein and SA were added to the third tube. PBS was added to the tubes containing only protein or SA to obtain equal reaction volumes in all tubes. Subsequently, the tubes were incubated on ice for 0.5-1 h after mixing. The shift results were assessed using $12 \%$ SDS-PAGE. 
Table I. Primers used to PCR amplify the target genes.
h4-1BBL-BirA-tag (660 bp)
RP1
5'-CCGCTCGAGTTATTCCGACCTCGGTGA AGGGAGTCCGG-3'
FP2
5'-AGCGGCGGCGGGGGCAGTGGAGGAGGGG GATCACGCGAGGGTCCCGAGCTTTCG-3'
FP3
5'-AGGCCCAGAAGATCGAGTGGCACGGAGGCGGAGGTAGCGGCGGCGGGGGCAGTGGAGG-3'
FP4 5'-CGCGGATCCGGTCTGAACGACATATTTGAGGCCCAGAAGATCGAGTGGCACGG-3'

hIL-21-BirA-tag (504 bp)

$\begin{array}{ll}\text { FP5 } & \text { 5'-GAATTCCATATGCAAGATCGCCACATGATTAGAATGC-3' } \\ \text { RP6 } & \text { 5'-CGAGCCCCCGCCGCCCGAACCCCCACCACCGGAATCTTCACTTCCGTGTGTTC-3' } \\ \text { RP7 } & \text { 5'-GAAGATGTCGTTGAGGCCCGATCCCCCTCCTCCCGAGCCCCCGCCGCCCGAACC-3' } \\ \text { RP8 } & \text { 5'-CCGCTCGAGTTAGTGCCATTCGATTTTTTGTGCTTCGAAGATGTCGTTGAGGCC-3' } \\ \text { BirA-tag } & \text { 5'-GGTCTGAACGACATATTTGAGGCCCAGAAGATCGAGTGGCAC-3' } \\ \text { Linker } & \text { 5'-GGTGGTGGGGGTTCGGGCGGCGGGGGCTCGGGAGGAGGGGGATCG-3' }\end{array}$

Bead-protein ligation reactions and detection of ligation efficiency. Appropriate amounts of DynabeadsM-280 Streptavidin were washed with PBST $(0.05 \%$ Tween-20 in PBS) and PBS, and resuspended in $500 \mu \mathrm{l}$ PBS. Excessive and equimolar h4-1BBL-BirA-tag-biotin and hIL-21-BirA-tag-biotin proteins were mixed with the prepared beads. The ligation reaction system was performed on a rotary mixer at $4^{\circ} \mathrm{C}$ for at least $6 \mathrm{~h}$. Mouse anti-His IgG-PE was added to a sample of the ligation reaction to detect the ligation efficiency of hIL-21-BirA-tagbiotin and the beads, while rabbit anti-His IgG-FITC was added to detect the ligation efficiency of h4-1BBL-BirA-tagbiotin and the beads, and mouse anti-His IgG-PE and rabbit anti-His IgG-FITC were consecutively used to detect the ligation efficiency of the two proteins and the beads. The same batch beads were used to repeat the experiments described above, but phosphate-buffered saline (PBS) was substituted for mouse anti-His IgG-PE, 4-1BB-His-tag protein and rabbit anti-His IgG-FITC as important controls to exclude the influence of non-specific ligation.

NK cell expansion. PBMCs were isolated from human concentrated leukocyte blood, resuspended in X-VIVO ${ }^{\mathrm{TM}} 15$ medium supplemented with $10 \%$ human $\mathrm{AB}$ serum, $10 \mathrm{mmol} / \mathrm{l}$ HEPES, $1 \mathrm{mmol} / 1$ sodium pyruvate, $2 \mathrm{mmol} / 1 \mathrm{~L}$-glutamine, $1 \%$ MEM NEAA, $1 \%$ penicillin-streptomycin and $100 \mathrm{IU} / \mathrm{ml}$ IL-2, seeded at a density of $1 \times 10^{6}$ cells $/ \mathrm{ml}$ onto 24 -well plates at $1 \mathrm{ml} /$ well, and subsequently incubated at $37^{\circ} \mathrm{C}$ in $5 \% \mathrm{CO}_{2}$. The following experimental groups were designated: two proteins (4-1BBL-IL-21-beads), single fixed and single soluble proteins (4-1BBL-beads+sIL-21, s4-1BBL+IL-21-beads), the mixture of the two soluble proteins (s4-1BBL+sIL-21), and the non-irritant control group. Each group was prepared with two parallel wells. On the first day, each group was co-incubated with PBMCs at 3:1. Repeated stimulation was performed weekly for 3 weeks. We should appropriately enlarge the culture system to ensure the viable cell density of $0.5-2 \times 10^{6} /$ $\mathrm{ml}$ during this stimulus.

Cell counting and flow cytometric analysis. After stimulation, we collected the cells of each group, separated the beads from the culture system with magnetic separation rack, and stained the cells with an LDS/PI mixture for cell counting using Guava flow cytometry. Approximately $5 \times 10^{5}$ cells were washed twice with PBS, followed by incubation with the appropriate antibodies (FITC-conjugated anti-human CD3 or APC-conjugated anti-human CD56) in a 100- $\mu 1$ reaction volume for $30 \mathrm{~min}$ at $4^{\circ} \mathrm{C}$. Subsequently, the cells were washed twice as described above and resuspended in $300 \mu \mathrm{l}$ of PBS. The data were acquired using a FACSCalibur flow cytometer (BD Biosciences) and analyzed using FlowJo software (Ashland, OR, USA).

In vitro killing experiment. K562-luc cells cultured in the basic RPMI-1640 medium supplemented with 10\% FBS, $1 \%$ penicillin-streptomycin were used as the target cells. The target cells were diluted to $1 \times 10^{5}$ cells $/ \mathrm{ml}$ in basic medium and plated onto 96 -well plates at $100 \mu \mathrm{l} /$ well. Subsequently, effector cells were added to the 96-well plates and incubated with the target cells for $4 \mathrm{~h}$ in $5 \% \mathrm{CO}_{2}$ at $37^{\circ} \mathrm{C}$ at ratios of $8: 1,4: 1,2: 1$, and 1:1, with 4 parallel experiment groups for each effector/target $(\mathrm{E} / \mathrm{T})$ ratio. Subsequently, we added luciferin and measured the total fluorescence in each well. The percent cytotoxicity was calculated using the following formula: cytotoxicity $(\%)=($ control group fluorescence value-experimental group fluorescence value) / control group fluorescence value x $100 \%$.

\section{Results}

The expression of BirA-tagged 4-1BBL and IL-21 recombinant proteins. 4-1BBL (4-1BB ligand or CD137 ligand) is a member of the tumor necrosis factor (TNF) ligand family. This 254-amino acid protein contains a 28-amino acid cytoplasmic domain, a 21-amino acid transmembrane domain, and a 205-amino acid extracellular domain (31). In the present study, the extracellular domain was cloned and the recombinant expression cassette is shown in Fig. 1A. Because 4-1BBL is a type II transmembrane protein (31), we generated an N-terminal BirA-tagged fusion protein to ensure that the protein functions normally, and the theoretical molecular 
A

Expression cassette of h4-1BBL-BirA-tag

\begin{tabular}{|l|l|l|l|l|}
\hline BamH I & BirA-tag & linker & h4-1BBL & Xho I \\
\hline
\end{tabular}

Expression cassette of hIL-21-BirA-tag

\begin{tabular}{|l|l|l|l|l|l|}
\hline $6 \times$ His & Nde I & IL-21 & linker & BirA-tag & Xho I \\
\hline
\end{tabular}

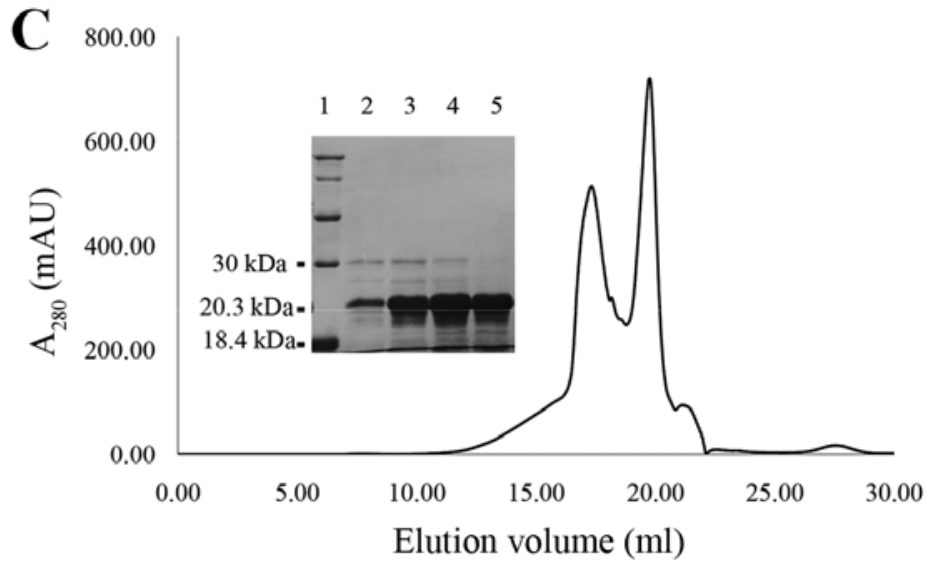

D

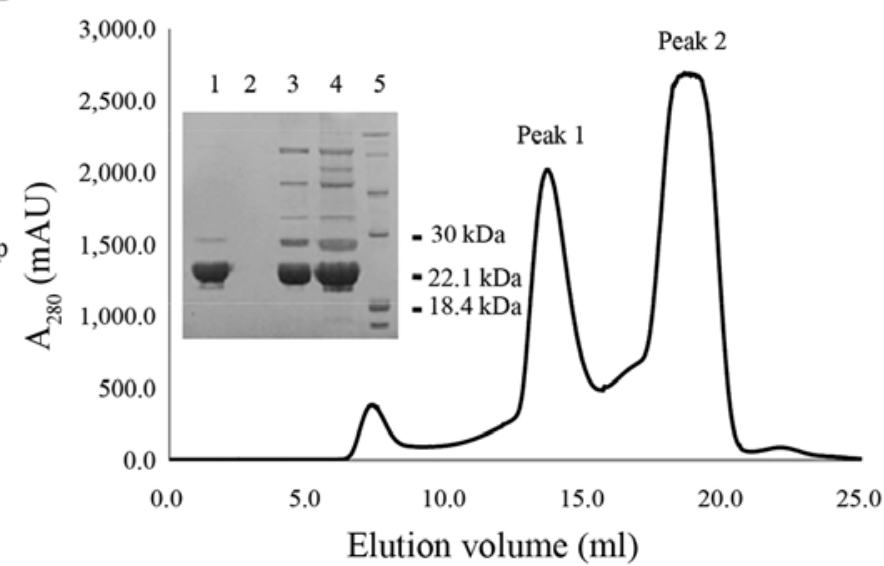

Figure 1. The expression of 4-1BBL and IL-21 BirA-tagged recombinant proteins. (A) Schematic representation of the expression cassettes for 4-1BBL and IL-21 BirA- tagged recombinant proteins. (B) The constructs were confirmed through gel electrophoresis of the PCR products for the targeted cassettes. Purification of hIL-21-BirA-tag (C) and h4-1BBL-BirA-tag-biotin (D) recombinant proteins through fast protein liquid chromatography (FPLC); the inserts show purified proteins separated through SDS-PAGE. (C) 1, The protein marker; and 2-5, the 4 tubes of protein collected from the first eluted peak, with $500 \mu$ of elute per tube. (D) Identification of the target peak using SDS-PAGE. 1, Protein peak 1; 2, protein peak 2; 3, h4-1BBL-BirA-tag; 4, unpurified h4-1BBL-BirA-tag-biotin; and 5, protein marker.

weight of the recombinant protein is $22.1 \mathrm{kDa}$. However, for human IL-21, a secreted protein belonging to the IL-15/IL-2 family, there is no significant functional difference between the $\mathrm{N}$ - and C-terminal fusion proteins (32). Therefore, we generated a C-terminal BirA-tagged fusion for this protein (Fig. 1A), the theoretical molecular weight of which is $\sim 20.3 \mathrm{kDa}$. These constructs were confirmed through gel electrophoresis of the PCR products for targeted cassettes (Fig. 1B).

The constructs were expressed in E. coli strain BL21 (DE3), and subsequently the h4-1BBL-BirA-tag, which forms a dimer in solution, was cut using PSP, and the recombinant proteins were purified using size-exclusion chromatography (Fig. 1D). The hIL-21-BirA-tag recombinant protein was obtained through denaturation and refolding $(33,34)$ and subsequently purified using size-exclusion chromatography (Fig. 1C).

Biotinylation efficiency of 4-1BBL and IL-21. Following biotinylation, h4-1BBL-BirA-tag-biotin protein was purified using FPLC (Fig. 1D). SDS-PAGE was used to identify the purified target protein, and the results showed that peak 1 was h4-1BBL-BirA-tag-biotin protein (Fig. 1D). However, for hIL-21-BirA-tag-biotin protein, the target protein could not be purified from the other proteins in the first experiment (data not shown). His-tag in hIL-21-BirA-tag protein was used to purify this protein using Ni-NTA beads, followed by further purification through FPLC (data not shown). Next, we used the SA electrophoretic mobility shift assay (35) to measure the biotinylation efficiency of these two proteins. The data revealed that these two types of protein were nearly $100 \%$ shifted with SA after conjugation, suggesting that both proteins were markedly and efficiently biotinylated (Fig. 2A). To ensure that the stimulation experiment could be effectively conducted, the bead-protein ligation efficiency was also examined. The FACS analysis demonstrated that each of two proteins could efficiently ligate with the beads, with an efficiency of $96.4 \%$ for h4-1BBL-BirA-tag-beads (Fig. 2B-b) and 97.8\% for hIL-21BirA-tag-beads (Fig. 2B-a). Moreover, these proteins could efficiently be simultaneously bound to the beads, with $\sim 80 \%$ efficiency (Fig. 2B-c).

Immobilized 4-1BBL and IL-21 induced the expansion of NK cells in vitro. After stimulation for 3 weeks, the expanded cells were harvested, purified from the culture system with magnetic separation rack and stained with LDS/PI to evaluate 


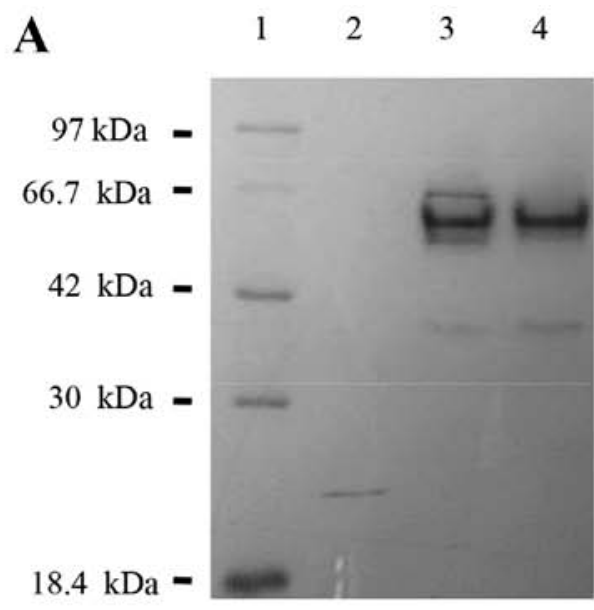

h4-1BBL-BirA-tag-biotin

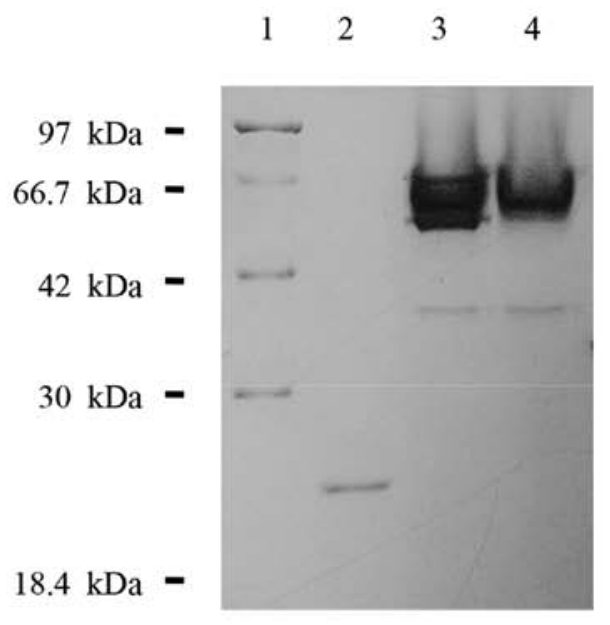

hIL-21-BirA-tag-biotin
B
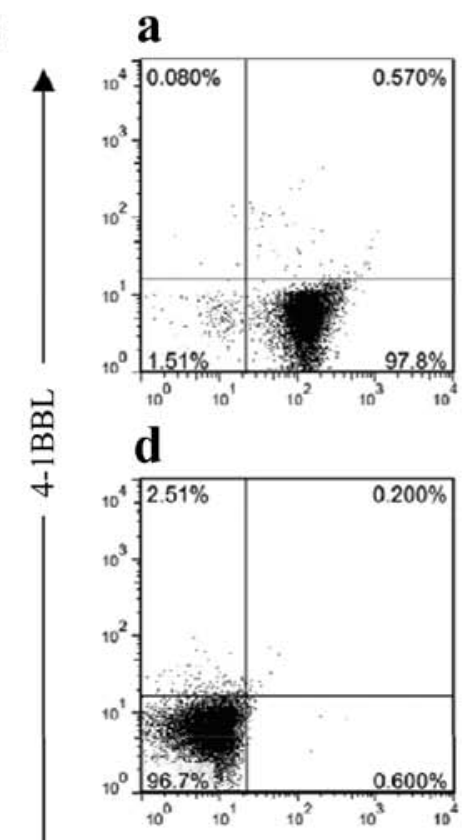

b

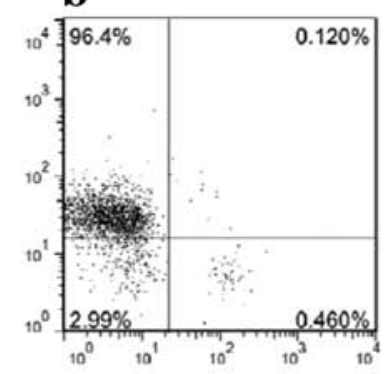

e

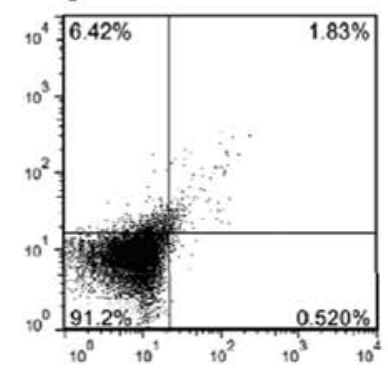

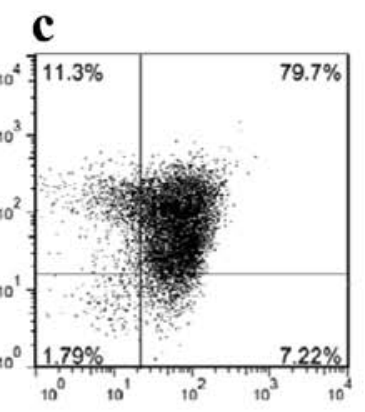
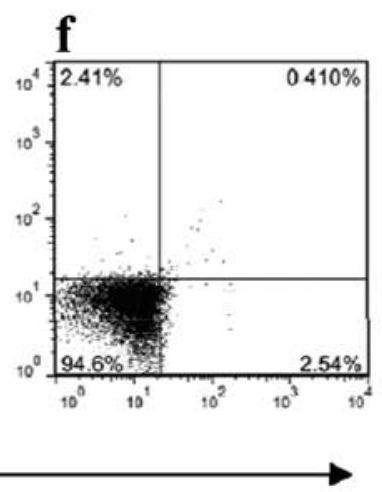

Figure 2. Biotinylation efficiency of 4-1BBL and IL-21. (A) Detection of the biotinylation efficiency of the target proteins using an SA electrophoretic mobility shift assay. 1, Protein marker; 2, purified and biotinylated protein; 3, protein and SA; and 4, SA. (B) Detection of the bead-protein ligation efficiency through FACS analysis: (a) to detect the efficiency of the hIL-21-BirA-tag-biotin and bead ligation; (b) to detect the efficiency of the h4-1BBL-BirA-tag-biotin and bead ligation; (c) to detect the efficiency of the ligation between the two types of proteins and beads; (d) substituting PBS for the 4-1BB-His protein in (b) to exclude the non-specificity of 4-1BB-His; (e) substituting PBS for the rabbit anti-His IgG-FITC in (b) to exclude the non-specificity of rabbit anti-His IgG-FITC; and (f) substituting PBS for the mouse anti-His IgG-PE in (a) to exclude the non-specificity of mouse anti-His IgG-PE.

cell viability using flow cytometry. Appropriate amounts of the cells from each group were sampled to detect the expression of the NK cell surface molecular markers CD3 and CD56 via flow cytometry and to determine the NK cell purity in each group. The lymphocyte profile before stimulation is shown in Fig. 3, indicating that the sample was obtained from a normal source, with $10-15 \%$ NK cells, consistent with previous studies, and this information was used to calculate the fold-expansion of each subset in each group of cells. Compared with the NK purity before stimulation in the non-irritant control group, the NK purity in each of the stimulation groups was markedly increased, particularly in the 4-1BBL-IL-21-beads stimulation group, obtaining $95 \%$ NK purity, which was the highest level detected among all groups (Fig. 3). This result suggests that 4-1BBL-IL-21-beads could elicit high-purity NK cells. Furthermore, according to the statistical and calculated results shown in Table II, the 4-1BBL-IL-21-bead-stimulation group achieved the highest fold-expansion of NK cells, with $\sim 140$-fold higher expansion than the other groups. Moreover, the NKT cells in each group showed a small increase in the ratio of lymphocytes, but a high proportion of $\mathrm{T}$ cells was no longer observed (Fig. 3), potentially reflecting the fact that 
Lymphocyte before stimulation

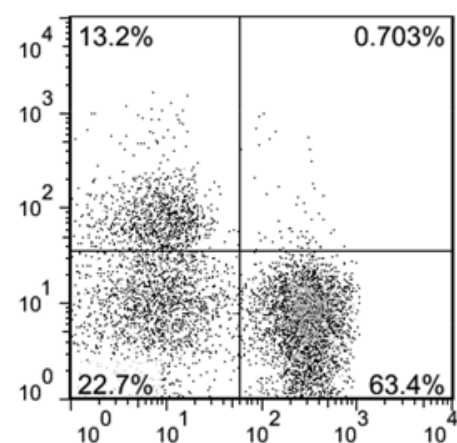

IL-21-Beads+s4-1BBL

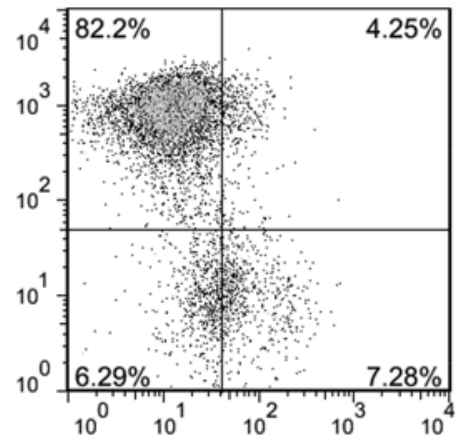

4-1BBL-IL-21-Beads

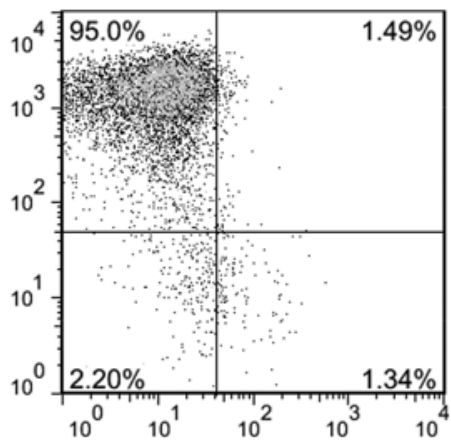

s4-1BBL+sIL-21

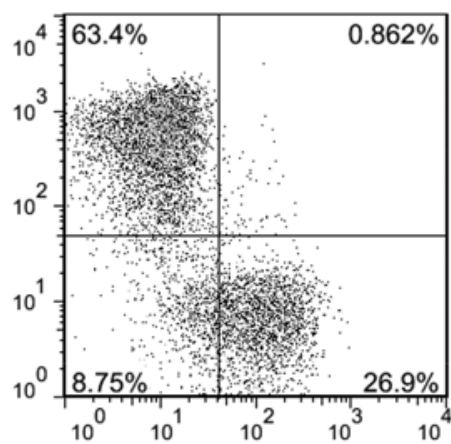

4-1BBL-Beads+sIL-21

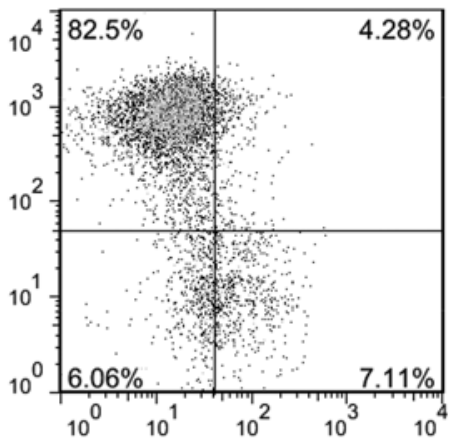

Non-irritant Control

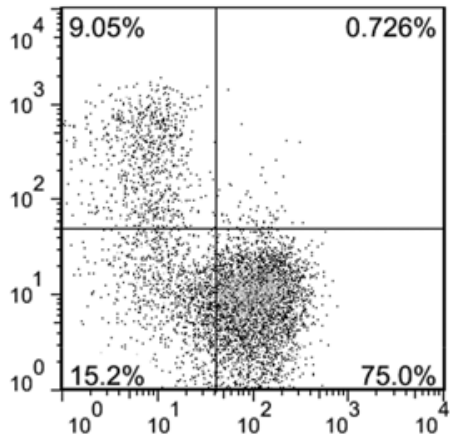

CD3/FITC

Figure 3. Immobilized 4-1BBL and IL-21 induced the expansion of NK cells in vitro. Eliciting high-purity NK cells using 4-1BBL-IL-21-beads. To determine the purity of the NK cells in the expanded cells, the expression of the NK cell surface molecular markers CD3 and CD56 was detected via flow cytometry. Lymphocytes before stimulation were the resting cells in PBMCs from concentrated human leukocyte blood. 4-1BBL-IL-21-beads were the irritant in the experimental group; 4-1BBL-beads+sIL-21, s4-1BBL+IL-21-beads, s4-1BBL+sIL-21 were, respectively the irritants in the different control groups; and the non-irritant control included the negative control without any form of stimulating factor. The experiment was repeated with samples from four different donors, and similar data were obtained.

Table II. The expansion of NK cells induced through 4-1BBL and IL-21 immobilized beads.

\begin{tabular}{|c|c|c|c|c|c|c|}
\hline $\begin{array}{l}\text { After stimulation } \\
\text { for } 3 \text { weeks }\end{array}$ & $\begin{array}{c}\text { Before } \\
\text { stimulation }\end{array}$ & $\begin{array}{l}\text { 4-1BBL- } \\
\text { IL-21-beads }\end{array}$ & 4-1BBL-beads & $\begin{array}{l}\text { IL-21-beads } \\
+ \text { +s4-1BBL }\end{array}$ & $\begin{array}{c}\text { sIL-21 } \\
+ \text { s4-1BBL }\end{array}$ & $\begin{array}{l}\text { Non-irritant } \\
\text { control }\end{array}$ \\
\hline $\begin{array}{l}\text { The fold expansion of } \\
\text { total PBMC numbers }\end{array}$ & $-/-$ & 19.477 & 1.975 & 1.983 & 3.175 & 2.579 \\
\hline \multicolumn{7}{|l|}{ NK cell } \\
\hline Purity (\%) & 13.2 & 95.00 & 82.50 & 82.20 & 63.40 & 9.05 \\
\hline Fold $^{\mathrm{a}}$ & $-/-$ & 140.17 & 12.34 & 12.35 & 15.24 & 1.77 \\
\hline \multicolumn{7}{|l|}{ NKT cell } \\
\hline Purity (\%) & 0.703 & 1.49 & 4.28 & 4.25 & 0.862 & 0.726 \\
\hline Fold & $-/-$ & 41.28 & 12.02 & 11.98 & 3.89 & 2.66 \\
\hline \multicolumn{7}{|l|}{$\mathrm{T}$ cell } \\
\hline Purity (\%) & 63.4 & 1.34 & 7.11 & 7.28 & 26.9 & 75.0 \\
\hline Fold & $-/-$ & 0.41 & 0.22 & 0.22 & 1.34 & 3.05 \\
\hline
\end{tabular}

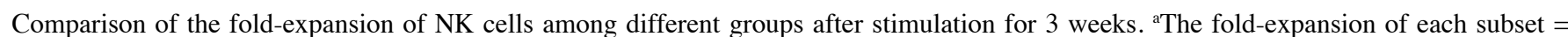
fold-expansion of total PBMCs $\mathrm{x}$ the purity of the subset after stimulus / the purity of the subset before stimulus. The experiment was repeated with samples from four different donors and similar data were obtained. 


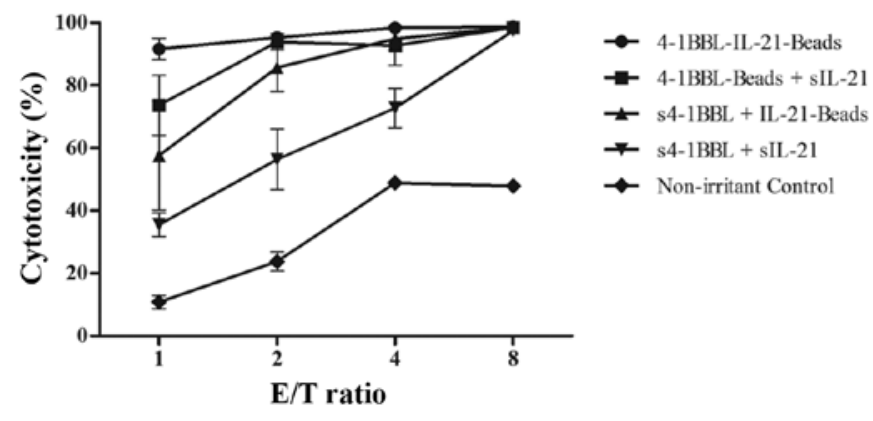

Figure 4. Expanded NK cells were effectively activated through immobilized 4-1BBL and IL-21. Compared with other stimulation groups and the non-irritant control group, the cells stimulated with 4-1BBL-IL-21-beads achieved the highest and most effective cytotoxicity against K562-luc cells at each E/T ratio. The data are presented as the means \pm SD $(n=4$; Student's t-test). The experiment was repeated with samples from four different donors, and similar data were obtained.

4-1BBL-IL-21-beads were beneficial for the expansion of NK cells but not T cells. Thus, 4-1BBL-IL-21-beads induced significant NK cell expansion.

Expanded NK cells were effectively activated through immobilized 4-1BBL and IL-21. Luciferase quantitative assay, a simple and sensitive method, has been increasingly and widely used to measure the cytolytic effects of various effector cells (36-38). In the present study, we used this method to test the cytotoxicity of stimulated cells against K562-luc cells. The results showed that compared with the control group and other stimulation groups, stimulation with 4-1BBL-IL-21beads achieved the best cytotoxicity against K562-luc cells at each $\mathrm{E} / \mathrm{T}$ ratio, and this cell group exhibited high cytotoxicity even at an $\mathrm{E} / \mathrm{T}$ ratio of $1: 1$, with nearly $100 \%$ cytotoxicity at an E/T ratio of 8:1 (Fig. 4). In contrast, the cells under single fixed and single soluble cytokine stimulation or mixed soluble cytokine stimulation showed higher killing activity than the cells in the control group, and cytotoxicity increased with increasing E/T ratio. Moreover, the control group cells also exhibited killing activity in relation to the small number of NK cells in the control group in the last graph of Fig. 3. Briefly, the cells stimulated with 4-1BBL-IL-21-beads showed the highest cytotoxicity against the K562-luc cells, indicating that NK cells could be highly activated using 4-1BBL-IL-21beads.

\section{Discussion}

The use of adoptive NK cell transfer to treat malignant tumors has gained increasing attention in the field of cell-based therapy and has made rapid progress in research, demonstrating promising clinically curative effects. However, it is difficult to obtain large-scale clinical-grade NK cells from donors; therefore, to overcome this limitation, many researchers have developed methods to amplify NK cells ex vivo (4). In the present study, we used solid phase cytokines of recombinant human IL-21 and 4-1BBL to proliferate the NK cells in PBMCs obtained from healthy donors. We not only achieved considerable NK cell expansion with high purity and cytotoxicity but also realized the effective segregation of the irritants and the expanded
NK cells, an outstanding point and innovation compared with previously published methods.

In recent years, a large number of expanded NK cells have been acquired from the blood of healthy individuals, showing 190-fold NK expansions induced through anti-CD3 and IL-2 after 21 days, but with low NK cell purity of only $55 \%$ (16). In addition, 1,000-fold NK expansions have also been obtained using the K562 cell line expressing 4-1BBL on the surface and weekly stimulation for 21 days. However, the initiating cells were negatively selected NK cells from PBMCs, and the feeder cell line could not be efficaciously removed from the final cultures (39). Moreover, the number of NK cells obtained from the blood of patients with myeloma showed on average 1,600-fold expansion after 20 days, but the cytotoxicity of these cells against K562 cells was nearly $60 \%$ at a $10: 1 \mathrm{E} / \mathrm{T}$ ratio and $<10 \%$ at a $1: 1 \mathrm{E} / \mathrm{T}$ ratio $(40)$.

In addition, we selected a three-week stimulation cycle based on previous studies using similar cytokines to stimulate NK cells $(14,15,30,39)$, and the cytotoxicity of the expanded NK cells was reported to peak after 3-5 weeks, followed by a decline, although with continuously growing numbers of NK cells (30). Thus, the differences in experimental conditions between the present study and previous reports suggest that it is worthwhile to examine the expansion and killing activity of NK cell through prolonged stimulation and increasing stimulation times.

Based on previous studies, we proposed that expanding NK cells with cultures containing feeder cells is more effective compared with cultures containing cytokines alone (4). For example, K562 cells with membrane-bound IL-15 and 4-1BBL were used as feeder cells to expand NK cells and generate large numbers of highly cytotoxic NK cells (41). Although the safeguards, such as using cultures of irradiated K562 cells and monitoring the cell growth and DNA synthesis rate, were provided, the inability to deplete the feeder cell line provided difficulties for clinical treatment. To overcome the problem of $\mathrm{T}$ and NKT cell contamination and overgrowth, the initial NK cells was purified from PBMCs $(13,42,43)$, but such purification procedure was time-consuming, arduous and costly. In this study NK cells in PBMCs without purification were used which certainly is a significant advantage.

Finally, an assessment of the anti-tumor activity of expanded NK cells in vivo is needed to meet clinical requirements although high purity and substantial fold-expansion of NK cells was achieved, and potent cytotoxicity was verified in vitro in the present study.

\section{Acknowledgements}

This study was supported by a grant from the Basic Research Program of China (973 Program, no. 2013CB531502), the Ministry of Science and Technology of China (S\&T major Program, no. 2012ZX1004701-001-002), and the National Nature Science Foundation of China (nos. 31370889, 31400754 and 31170829).

\section{References}

1. Nagler A, Lanier LL, Cwirla S and Phillips JH: Comparative studies of human FcRIII-positive and negative natural killer cells. J Immunol 143: 3183-3191, 1989. 
2. Lanier LL, Le AM, Civin CI, Loken MR and Phillips JH: The relationship of CD16 (Leu-11) and Leu-19 (NKH-1) antigen expression on human peripheral blood NK cells and cytotoxic T lymphocytes. J Immunol 136: 4480-4486, 1986.

3. Davies JO, Stringaris K, Barrett AJ and Rezvani K: Opportunities and limitations of natural killer cells as adoptive therapy for malignant disease. Cytotherapy 16: 1453-1466, 2014.

4. Childs RW and Berg M: Bringing natural killer cells to the clinic: Ex vivo manipulation. Hematology (Am Soc Hematol Educ Program) 2013: 234-246, 2013.

5. Vivier E, Raulet DH, Moretta A, Caligiuri MA, Zitvogel L, Lanier LL, Yokoyama WM and Ugolini S: Innate or adaptive immunity? The example of natural killer cells. Science 331: 44-49, 2011

6. Ljunggren H-G and Malmberg K-J: Prospects for the use of NK cells in immunotherapy of human cancer. Nat Rev Immunol 7: 329-339, 2007.

7. Srivastava S, Lundqvist A and Childs RW: Natural killer cell immunotherapy for cancer: A new hope. Cytotherapy 10: 775-783, 2008

8. Miller JS, Soignier Y, Panoskaltsis-Mortari A, McNearney SA, Yun GH, Fautsch SK, McKenna D, Le C, Defor TE, Burns LJ et al: Successful adoptive transfer and in vivo expansion of human haploidentical NK cells in patients with cancer. Blood 105: 3051-3057, 2005.

9. Klingemann $\mathrm{H}$ and Boissel L: Targeted cellular therapy with natural killer cells. Horm Metab Res 40: 122-125, 2008.

10. Sutlu T, Stellan B, Gilljam M, Quezada HC, Nahi H, Gahrton G and Alici E: Clinical-grade, large-scale, feeder-free expansion of highly active human natural killer cells for adoptive immunotherapy using an automated bioreactor. Cytotherapy 12: 1044-1055, 2010.

11. Herberman RB: Cancer immunotherapy with natural killer cells. In: Seminars in Oncology. Elsevier, pp27-30, 2002.

12. Klingemann H-G and Martinson J: Ex vivo expansion of natural killer cells for clinical applications. Cytotherapy 6: 15-22, 2004.

13. Berg M, Lundqvist A, McCoy P Jr, Samsel L, Fan Y, Tawab A and Childs R: Clinical-grade ex vivo-expanded human natural killer cells up-regulate activating receptors and death receptor ligands and have enhanced cytolytic activity against tumor cells. Cytotherapy 11: 341-355, 2009.

14. Imai C, Iwamoto S and Campana D: Genetic modification of primary natural killer cells overcomes inhibitory signals and induces specific killing of leukemic cells. Blood 106: 376-383, 2005.

15. Denman CJ, Senyukov VV, Somanchi SS, Phatarpekar PV, Kopp LM, Johnson JL, Singh H, Hurton L, Maiti SN, Huls MH, et al: Membrane-bound IL-21 promotes sustained ex vivo proliferation of human natural killer cells. PLoS One 7: e30264, 2012.

16. Carlens S, Gilljam M, Chambers BJ, Aschan J, Guven H, Ljunggren HG, Christensson B and Dilber MS: A new method for in vitro expansion of cytotoxic human CD3-CD56 ${ }^{+}$natural killer cells. Hum Immunol 62: 1092-1098, 2001

17. Smith CA, Farrah T and Goodwin RG: The TNF receptor superfamily of cellular and viral proteins: Activation, costimulation, and death. Cell 76: 959-962, 1994.

18. DeBenedette MA, Shahinian A, Mak TW and Watts TH: Costimulation of CD28- T lymphocytes by 4-1BB ligand. J Immunol 158: 551-559, 1997.

19. Hurtado JC, Kim SH, Pollok KE, Lee ZH and Kwon BS: Potential role of 4-1BB in T cell activation. Comparison with the costimulatory molecule CD28. J Immunol 155: 3360-3367, 1995.

20. Vinay DS and Kwon BS: 4-1BB signaling beyond T cells. Cell Mol Immunol 8: 281-284, 2011.

21. Melero I, Johnston JV, Shufford WW, Mittler RS and Chen L: NK1.1 cells express 4-1BB (CDw137) costimulatory molecule and are required for tumor immunity elicited by anti-4-1BB monoclonal antibodies. Cell Immunol 190: 167-172, 1998.

22. Wu C, Guo H, Wang Y, Gao Y, Zhu Z and Du Z: Extracellular domain of human 4-1BBL enhanced the function of cytotoxic T-lymphocyte induced by dendritic cell. Cell Immunol 271: 118-123, 2011.

23. Guo H, Jiang W, Liu W, Gao Y, Yang M, Zhou Y, Wang J, Qi J, Cheng X, Zhu Z, et al: Extracellular domain of 4-1BBL enhanced the antitumoral efficacy of peripheral blood lymphocytes mediated by anti-CD3 x anti-Pgp bispecific diabody against human multidrug-resistant leukemia. Cell Immunol 251: $102-108,2008$
24. Rabu C, Quéméner A, Jacques Y, Echasserieau K, Vusio P and Lang F: Production of recombinant human trimeric CD137L (4-1BBL). Cross-linking is essential to its T cell co-stimulation activity. J Biol Chem 280: 41472-41481, 2005.

25. Parrish-Novak J, Dillon SR, Nelson A, Hammond A, Sprecher C, Gross JA, Johnston J, Madden K, Xu W, West J, et al: Interleukin 21 and its receptor are involved in NK cell expansion and regulation of lymphocyte function. Nature 408: 57-63, 2000

26. Parrish-Novak J, Foster DC, Holly RD and Clegg $\mathrm{CH}$ : Interleukin-21 and the IL-21 receptor: Novel effectors of NK and T cell responses. J Leukoc Biol 72: 856-863, 2002.

27. Zeng R, Spolski R, Casas E, Zhu W, Levy DE and Leonard WJ: The molecular basis of IL-21-mediated proliferation. Blood 109: 4135-4142, 2007.

28. Burgess SJ, Marusina AI, Pathmanathan I, Borrego F and Coligan JE: IL-21 down-regulates NKG2D/DAP10 expression on human $\mathrm{NK}$ and CD8 ${ }^{+} \mathrm{T}$ cells. J Immunol 176: 1490-1497, 2006.

29. Mehta DS, Wurster AL and Grusby MJ: Biology of IL-21 and the IL-21 receptor. Immunol Rev 202: 84-95, 2004

30. Wang X, Lee DA, Wang Y, Wang L, Yao Y, Lin Z, Cheng J and Zhu S: Membrane-bound interleukin-21 and CD137 ligand induce functional human natural killer cells from peripheral blood mononuclear cells through STAT-3 activation. Clin Exp Immunol 172: 104-112, 2013

31. Goodwin RG, Din WS, Davis-Smith T, Anderson DM, Gimpel SD, Sato TA, Maliszewski CR, Brannan CI, Copeland NG, Jenkins NA, et al: Molecular cloning of a ligand for the inducible $\mathrm{T}$ cell gene 4-1BB: A member of an emerging family of cytokines with homology to tumor necrosis factor. Eur J Immunol 23: 2631-2641, 1993.

32. Fa P, Zhang Z, Li J, Hu Z and Gao J: Expression, purification and bioactivity evaluation of streptavidin-tagged human interleukin-21 fusion protein. Nan Fang Yi Ke Da Xue Xue Bao.30: 1240-1243, 1249, 2010 (In Chinese)

33. Lee CM, McGuire H, Basten A, King C and Christ D: Expression, purification and characterization of recombinant interleukin-21. J Immunol Methods 362: 185-189, 2010.

34. Asano R, Kudo T, Makabe K, Tsumoto K and Kumagai I: Antitumor activity of interleukin-21 prepared by novel refolding procedure from inclusion bodies expressed in Escherichia coli. FEBS Lett 528: 70-76, 2002.

35. Garboczi DN, Utz U, Ghosh P, Seth A, Kim J, VanTienhoven EA, Biddison WE and Wiley DC: Assembly, specific binding, and crystallization of a human TCR-alphabeta with an antigenic Tax peptide from human T lymphotropic virus type 1 and the class I MHC molecule HLA-A2. J Immunol 157: 5403-5410, 1996.

36. Fu X, Tao L, Rivera A, Williamson S, Song XT, Ahmed N and Zhang X: A simple and sensitive method for measuring tumorspecific T cell cytotoxicity. PLoS One 5: e11867, 2010.

37. Brown CE, Wright CL, Naranjo A, Vishwanath RP, Chang WC, Olivares S, Wagner JR, Bruins L, Raubitschek A, Cooper LJ, et al: Biophotonic cytotoxicity assay for high-throughput screening of cytolytic killing. J Immunol Methods 297: 39-52, 2005.

38. Ma J, Han H, Liu D, Li W, Feng H, Xue X, Wu X, Niu G, Zhang G, Zhao Y, et al: HER2 as a promising target for cytotoxicity T cells in human melanoma therapy. PLoS One 8: e73261, 2013

39. Zhang H, Cui Y, Voong N, et al: Activating signals dominate inhibitory signals in CD137L/IL-15 activated natural killer cells. J Immunother 34: 187-195, 2011

40. Alici E, Sutlu T, Björkstrand B, Gilljam M, Stellan B, Nahi H, Quezada HC, Gahrton G, Ljunggren HG and Dilber MS: Autologous antitumor activity by NK cells expanded from myeloma patients using GMP-compliant components. Blood 111: 3155-3162, 2008

41. Fujisaki H, Kakuda H, Shimasaki N, Imai C, Ma J, Lockey T, Eldridge P, Leung WH and Campana D: Expansion of highly cytotoxic human natural killer cells for cancer cell therapy. Cancer Res 69: 4010-4017, 2009.

42. Lapteva N, Durett AG, Sun J, Rollins LA, Huye LL, Fang J, Dandekar V, Mei Z, Jackson K, Vera J, et al: Large-scale ex vivo expansion and characterization of natural killer cells for clinical applications. Cytotherapy 14: 1131-1143, 2012.

43. Luhm J, Brand J-M, Koritke P, Höppner M, Kirchner H and Frohn C: Large-scale generation of natural killer lymphocytes for clinical application. J Hematother Stem Cell Res 11: 651-657, 2002 . 